\title{
The Effect of Oral and Written Contextualization of Collocation Instruction on the Learning and Retention of Semantically Semitransparent English Collocations
}

\section{Negar Hasani ${ }^{1} \&$ Adel Dastgoshadeh ${ }^{1 *}$}

* Correspondence:

adastgoshadeh@gmail.com

Department of English, Sanandaj

Branch, Islamic Azad University,

Sanandaj, Iran

Received: 18 December 2020

Revision: 1 March 2021

Accepted: 28 March 2021

Published online: 20 June 2021

\begin{abstract}
This study aimed to investigate the effect of oral and written contextualization of collocation teaching on the learning and long-term retention of semantically semitransparent collocations by Iranian EFL learners. To this end, 65 students were selected from a cohort of students who were studying English at an English language institute in Sanandaj, Iran. They were randomly divided into two groups based on whether they would receive oral and written contextualization. Then, each group was further subdivided into two groups based on whether they would receive instruction on the concept of semantic transparency, yielding two experimental groups each including 16 learners as the Written Practice Group plus and minus instruction on the concept of semantic transparency, two experimental groups as the Oral Practice Group plus and minus instruction on the concept of semantic transparency, including 16 and 17 learners, respectively. Their initial general English proficiency was measured through the Preliminary English Test (PET), and they were pretested on semitransparent collocations through a researcher-made collocation test. Finally, two equivalent researcher-made collocation tests were used to measure the participants' learning and retention on the immediate and delayed posttests. The results of two-way ANOVAs revealed that the oral group outperformed the written group on the immediate and delayed posttests and the plus transparency instruction groups in each modality (oral and written) group outperformed the minus transparency instruction groups. The interpretations of the findings and their pedagogical implications have been discussed.
\end{abstract}

Keywords: oral contextualization, written contextualization, semantic transparency, semitransparent collocations, retention 


\section{Background and Purpose}

The role of lexicon study and lexical knowledge in learning a second language has been emphasized in second language acquisition (SLA) literature (Shehata, 2008; Unver, 2018). Some people have even gone so far as to state that despite the language learners' command of the grammar of the target language, communication will break down without a sufficient repertoire of lexical knowledge for conveying the intended meaning (McCarthy, 1990; Milton, 2009). Milton (2009), arguing that vocabulary is not an optional or trivial element of second language knowledge, commented that "words are the building blocks of language and without them there is no language" (p. 3). In addition to the importance attached to the role of vocabulary in learning a second language, the role of word combinations, known as formulaic language, has been fore-grounded by scholars in the field (Pei, 2008; Sehata, 2008; Vural, 2010). As a subset of prefabricated linguistic chunks, collocation has attracted lots of attention in the SLA literature in the past decades (Gitzaki, 1999; Webb \& Kagimoto, 2011).

The concept of 'collocation' was first introduced by Palmer (1938) in his pioneering work 'A Grammar of English Words.' Later, it was proposed as a technical term into the literature by Firth (1957, p. 194) whereby the phrase "meaning by collocation" became established as one of his proposed "modes of meaning." Collocations or the frequently co-occurring syntagmatic units of two-to-three words such as loud voice and interest in are a subcategory of formulaic chunks. They are, in fact, "word combinations which involve two lexical items, one of which is selected arbitrarily by the other lexical item to convey a particular meaning" (Melcuk, 1998, p. 14). "The combination is not a fixed expression but there is a greater than chance likelihood that the words will co-occur" (Jackson, 1988, p. 96). Mastery of these formulaic sequences has been considered a central component of communicative competence and is supposed to enable native speakers to process language fluently and idiomatically and fulfill basic communicative needs. Collocational competence is believed to be equally important for L2 learners, which is, in the meantime, supposed to be a language phenomenon acquired late and often not mastered very well even by fairly competent L2 language learners.

Moreover, as N. Ellis $(2001,2003, \& 2005)$ maintains, memory and the ability to chunk language into units play an important role in language learning and use. The facilitating processing effects of collocations or recurrent lexical chunks in the form of lexical priming have also been reiterated by Hoey (2005). Mastery of formulaic sequences (FS) is also important for L2 learners. The role of FSs and more specifically the role of collocations have increasingly been highlighted in SLA research during the last two decades (Barfield \& Gyllstad, 2009; Granger \& Meunier, 2008; Lewis, 2000; Reza \& Ashouri, 2016; Schmitt, 2004; Slezak, 2015; Wood, 2010). More specifically, their role in the fluent use of a second language and the native-like selection of meaning-creating lexical chunks warrant their being the focus of extensive enquiry (Nation, 2001).

Different criteria have been put forward for classifying collocations in the literature. For instance, one can refer to Nation's (2001) ten scalar criteria most of which are grammatical in nature. Laufer and Waldman (2011) proposed restricted co-occurrence and relative transparency of meaning as two criteria for distinguishing collocations. However, there are two major approaches to the identification of collocations (Barfield \& Gyllstad, 2009; Granger \& Pacquot, 2008). First, there is the data-driven or frequency-based approach which relies on the frequency of occurrence of collocations and their constituent words in the language corpora without taking into consideration the syntactic and semantic relationships between the constituent elements of a collocation. Second, there is the phraseological approach which takes into account the semantic relations between the constituents of a collocation without looking at the frequency of that collocation. Of particular relevance to this latter view is the criterion of semantic transparency which influences the degree of saliency of collocations and, consequently, the degree of difficulty with which L2 learners learn and remember them.

The concept of semantic transparency was proposed as a distinctive feature for distinguishing between different kinds of collocations (Bartsch, 2004). Based on this criterion, when the meaning of two constituent words which make up a collocation is known to the learner (e.g., main idea), the collocation is called a fully transparent collocation. However, when a collocation is not so straightforward in the meaning of its constituent elements, it is either a semi-transparent collocation (e.g., take a course) or a non-transparent collocation (e.g., take sides). In the former case, the meaning of one of the constituent lexical items is more likely to be known by the learner, while in the latter case the meanings of both constituents are unclear to him. The meaning of a semi-transparent collocation is more difficult to decode than the literal meaning of its constituent parts, but it is less salient than the meaning of a non-transparent collocation. Such collocations, as Nesselhauf $(2003,2005)$ argued, should be the main focus of L2 research and teaching in order to find 
appropriate ways for raising language learners' attention to them and their structures. However, Godfroid, Boers, and Housen (2013) argued that collocations which are made up of familiar words are less likely to be attended to by language learners simply because the familiarity of their constituent words renders them less salient.

These hypotheses seem to constitute remarkable gaps in collocation research because a sufficient number of empirical studies will be needed to explore whether any instructional intervention is likely to influence the learning and retention of semantically semi-transparent and non-transparent collocations. In other words, on the one hand, there is the need to investigate the effect of contextualization of collocation instruction on the learning of semantically semi-transparent collocations. On the other hand, further research is needed to compare such effects across semantically semitransparent and non-transparent collocations. In the context of the present study, the former gap is under focus.

\subsection{Statement of the Problem}

Although different studies have investigated the learning of collocations focusing on the different aspects of teaching and learning collocations, it seems that the question of whether modality-based contextualization influences the learning and retention of semantically semi-transparent collocations has remained under-researched. Therefore, the problem of interest in the present study relates to the effect of using conversations and paragraph writing on EFL learners' learning and retention of collocations. Put more clearly, the problem in this study is to bridge this gap in collocation research by exploring whether contextual teaching of collocations implemented through L2 learners' engagement in conversations and paragraph writing would differentially influence their learning and retention of collocations. Two studies by Mirhassani and Talebi (2007) and Zarei and Tondaki (2015) on the effect of context (sentence writing) on EFL learners' retention of idioms also revealed that sentence writing significantly contributed to the recall and recognition of idioms. Zaabalawi and Gould (2017) report on the results of a study where a writing course instructor raised an experimental group's awareness of the existence of collocations and provided students with adequate practice of the use of such structures. Specifically, it seems that the study's exposure intervention does enhance unprompted/natural native-speaker performance with collocations.

\subsection{The Present Study}

As semantic transparency is an objective criterion for the saliency of a given collocation and determines the degree of difficulty with which a language learner learns a collocation and also, in line with Nesselhauf's (2003, 2005) proposed problematicity of semi-transparent collocations, the present study has aimed to investigate the effect of collocation teaching embedded in oral and written contexts with and without explicit reference to semantic transparency on the learning and long-term retention of semi-transparent collocations. More specifically, this study has aimed to answer the following questions.

\subsection{Research Questions}

The research questions of this study are as follows:

1. Do conversation-based contextualization and paragraph writing contextualization differentially influence intermediate Iranian EFL learners' learning of semitransparent collocations?

2. Do conversation-based contextualization and paragraph writing contextualization differentially influence intermediate Iranian EFL learners' retention of semitransparent collocations?

3. Does instruction on the concept of semantic transparency of English collocations interact with conversation-based contextualization and paragraph writing contextualization in influencing intermediate Iranian EFL learners' learning of semitransparent collocations?

4. Does instruction on the concept of semantic transparency of English collocations interact with conversation-based contextualization and paragraph writing contextualization in influencing intermediate Iranian EFL learners' retention of semitransparent collocations?

\subsection{Research Hypotheses}

The hypotheses of this research are as follows:

1. Conversation-based contextualization and paragraph writing contextualization do not differentially influence intermediate Iranian EFL learners' learning of semitransparent collocations. 
2. Conversation-based contextualization and paragraph writing contextualization do not differentially influence intermediate Iranian EFL learners' retention of semitransparent collocations.

3. Instruction on the concept of semantic transparency of English collocations does not interact with conversation-based contextualization and paragraph writing contextualization in influencing intermediate Iranian EFL learners' learning of semitransparent collocations.

4. Instruction on the concept of semantic transparency of English collocations does not interact with conversation-based contextualization and paragraph writing contextualization in influencing intermediate Iranian EFL learners' retention of semitransparent collocations.

\section{Review of the Literature}

A review of the literature indicates that the implications of such theoretical underpinnings have been applied to research on the development of idiomatic knowledge but not so for collocation research. Different techniques such as teaching idioms through lists, translation, synonyms, antonyms, definitions, drawings, and categorizing are used by teachers (Khabiri \& Masoumpanah, 2012; Zou, 2017).

As McCarthy (1990) pointed out, most researchers have primarily relied on contextual presentation and teaching of idioms in order to facilitate their learning and retention by L2 learners. Mendis and Simpson (2003) also emphasized the role of spoken and written discourse for contextualizing idiom instruction. Such theoretical and empirical evidence suggests that using context can enhance learning idioms as part of the linguistic repertoire needed to perform successfully in a second language. Regarding collocation research, some studies have addressed the comparison of native versus non-native speakers' productive use of collocations (Nesselhauf, 2003), and the effect of L1 transfer on the use of L2 collocations (Jiang, 2009; Nesselhauf, 2003).

Still, some other studies (Koya, 2005; Laufer \& Waldman, 2011; Zhang, 2017) have measured both receptive and productive knowledge of collocations. Koya's (2005) study indicated that language learners possessed more receptive knowledge of collocations than productive knowledge. Laufer and Waldman's (2011) study showed that language learners had problems in the productive use of collocations, but they did not experience problems in their receptive understanding of collocations.

In a study exploring the effectiveness of explicit instruction of collocations through focused exercises, Boers, Dang, and Strong (2017) also found that such exercises enhance L2 collocation knowledge. Gyllstad and Wolter (2015), checking the effect of the semantic transparency of collocations on their processing by L2 learners, realized that the semantically semi-transparent collocations hindered the processing of collocations.

Keshavarz and Taherian (2018) carried out a study to examine the effect of explicit instruction of collocations on EFL learners' language proficiency and found out that raising students' awareness of collocations through explicit ways resulted in improvement in language proficiency. Snoder (2017) studied the effects of three vocabulary teaching constructs (involvement load, spacing, and intentionality) on the learning of English verb-noun collocations and came up with significant effects on the three measures for intentional learning when compared to incidental learning.

Regarding the degree of transparency as indicated by the congruence between the constituents of collocations, the study by Peters (2016) showed that incongruent collocations were more difficult to learn than congruent ones. Sonbul and Schmitt (2013) tested the effects of three different conditions of collocation instruction; namely, instructed (collocations taught in isolation), enhanced (collocations presented in red font and bolded), and unenhanced acquisition of collocations. They found that the learners' explicit knowledge improved under all the treatment conditions, on both the immediate and delayed posttests.

A study by Khodareza and Ashouri (2016), investigating the effect of lexical collocation instruction on Iranian intermediate EFL learners' vocabulary size, suggests that lexical collocation instruction contributed to the expansion of vocabulary knowledge. Szudarski and Carter (2016) also showed that explicit instruction of collocations in the form of input flood and input enhancement together with explicit explanations about collocations and their structure had a positive effect on the acquisition and retention of collocations. 


\section{Methodology}

\subsection{Participants}

The participants of this study were 76 female intermediate EFL students from a Kurdish-Persian language background, studying English at an English language institute in Sanandaj, Iran. They attended classes on even days and were selected through convenient available sampling. Out of those 76 students, 71 students who scored between one standard deviation above and below the mean on the general English proficiency test (PET) were selected as the participants to be pretested on semitransparent English collocations and the rest were excluded from the design of the study. Then, out of the remaining 71 students, 65 students (all female) who answered below 20 percent of the questions on the collocation pretest were considered as not knowing the target collocations and, therefore, were selected as the ultimate participants of the study. Finally, they were randomly assigned to four experimental groups.

\subsection{Design of the Study}

As the selection of the participants was based on convenience non-random sampling, this study was carried out following a pretest, treatment, posttest quasi-experimental design. Two types of treatment each with two levels constituted the independent variables. One instructional treatment was oral and written practice of English collocations contextualized in oral and written tasks, and the other independent variable was instruction on the concept of semantic transparency along with the provision of examples and absence of this instruction in half of the groups. The dependent variables were the participants' learning and retention of semitransparent English collocations as measured by the collocation posttests 1 and 2. Gender was held constant in this study and age might have functioned as an intervening variable.

\subsection{Instruments}

The instruments that were used in this study included the assessment materials, the course book, and the tasks and activities that were utilized for each group. The assessment materials included a test of general English proficiency, a collocation pretest and two collocation posttests, i.e. an immediate posttest and a delayed posttest. The general English proficiency test (PET) includes four sections of listening, speaking, reading, and writing. The researchers used three sections of listening, reading, and writing. The internal consistency of this test was calculated through Chronbach's alpha which yielded a reliability index of .87 .

Based on the selected collocations, three collocation tests were developed by the researchers for the purpose of this study. One test, consisting of 90 multiple-choice items, was developed by the researchers and used as the collocation pretest. It was piloted on a similar group of male learners and three items which were identified as malfunctioning were removed from the test. Also, some choices were either modified. The internal consistency of the remaining test was computed using Chronbach's alpha, yielding a reliability index of .87. Then, it was administered to the real participants to measure their prior knowledge of the semitransparent English collocations and identify those collocations which would be left unanswered by the learners. The internal consistency reliability of the real administration was also computed using Chronbach's alpha which produced an index of.87. The results showed that 60 collocations turned out to be the most difficult for the majority of the students. Those collocations were selected as the ones to be included in the treatment sessions and on the posttests.

Another test, which was developed by the researchers, was a parallel-form test which was used for the immediate posttest and consisted of 30 multiple-choice items on semitransparent English collocations. After the pilot study, a few distracters which appeared not be functioning properly were modified. It enjoyed a reliability index of .92. Therefore, it was used as the immediate posttest after the treatment and its correlation with the pretest on its real administration was computed which produced a correlation coefficient of .55 , indicating its equivalence with the pretest.

The third test was another researcher-made parallel-form test, again including 30 multiple-choice items on semitransparent English collocations and was used as the delayed posttest. It had also been piloted previously. After ensuring its reliability on the pilot phase (.94), it was used as the delayed posttest and its correlation with the immediate posttest was computed using Pearson correlation, giving an index of .97 .

The content validity of the pretest and the posttests was ensured through exposing the tests to the judgment of the same experts who had decided on the selection of the collocations. They discussed the content of the developed tests until final agreement was reached. All versions of the collocation tests were piloted on a similar group of learners. 
The pilot group consisted of 15 male EFL learners, with the same level as the real participants, who were studying at the same English language institute and received the same instruction. The course book was the American English File 1 with its accompanying tasks and activities as the regular syllabus of the classes. Also, some oral and written tasks had been planned by the researchers and were used to contextualize the instruction and practice of the collocations during the treatment period.

\subsection{Procedure}

For the purpose of the instructional treatment and the development of the collocation tests, 90 semitransparent collocations were selected from the Academic Collocation List (ACL) compiled by Ackermann and Chen (2013). The collocations were selected based on the criterion of semantic transparency as judged by a panel of experts in the field who reached an agreement on the degree of semantic transparency of the selected collocations and judged them to be semantically semitransparent. The criterion of transparency judgment, following Frisson, Niswander-Klement, and Pollatsek (2008), Nesselhauf (2003, 2005), and Henriksen (undated), was based on whether the two constituent words of a given collocation were both transparent in meaning (transparent-transparent), e.g., major catastrophe; both were opaque (opaque-opaque), e.g., take sides; or one was opaque with the other one transparent (opaque-transparent), e.g., take a course. Those collocations which had one opaque and one transparent word were considered as semantically semitransparent collocations by the raters. Then, the different groups of participants received the different versions of the treatment as follows.

The treatment lasted for seven sessions for each group. In the first Oral Practice Group (16 learners) with instruction on the semantic transparency of English collocations, some semantically semitransparent collocations (8 to 9 collocations) were taught in each session. This instruction included clarifying the concept and structure of collocations along with providing examples and illustrating the different collocation types in terms of the degree of their semantic transparency with examples of each type.

More precisely, the researchers explained that collocations are made up of at least two words and their meaning cannot necessarily be deciphered from the meaning of the individual words which constitute them. And examples were provided along with the further explanation that collocations can be classified into three distinct categories based on the degree of their semantic transparency. Then, the concept of semantic transparency was elaborated as whether the meaning of a collocation could be deciphered based on the meaning of each of the constituent words in that collocation.

The concept of semantic transparency was illustrated through such examples as major catastrophe (fully transparent), take a course (semi-transparent), and take sides (non-transparent). Then, the researchers embedded collocation instruction in an oral task each session. She implemented a planned focus-on-form (FoF) instruction whereby the learners were asked to design conversations in pairs using the newly presented collocations. Each pair had to practice their conversation and then act it out for the whole class, after which the class was engaged in meaning negotiation and question and answer exchanges based on each acted-out conversation.

They also commented on the accuracy of using the collocations by each pair of students. The researchers also provided the class with feedback about each pair's activity. Any questions posed by the students about the structure, meaning, and use of the collocations were answered either by peers or by the researchers whenever necessary. Question-andanswer activities using the collocations followed in group discussion or pair-work formats until collocations seemed to have been acquired by the students.

The second Oral Practice Group (17 learners) received the same form of instruction without any instruction on the semantic transparency of collocations. The first Written Practice Group (16 learners) with instruction on the semantic transparency of collocations, received the same explicit instruction on semantic transparency which was given to the first oral group, as explained above. Then, the researchers contextualized collocation instruction in writing activities in the form of paragraph writing which was operationalized as planned focus-on-form (FoF) instruction which included warm-up activities on the preselected collocations under study including brainstorming on their possible meanings and requiring the learners to produce written sentences in which they used those collocations followed by free sentence and paragraph writing by using as many of the collocations as possible.

Then, samples of the students' written scripts were collected and analyzed collaboratively by the researchers and the peers in class as class time allowed and feedback was given about the appropriate use of collocations in the written sentences and/or paragraphs. This collaborative feedback procedure was to further engage the students in the learning process and raise their consciousness about the correct use of collocations. Finally, the written scripts were returned 
to the learners in the following session with the researchers' comments written in the margins. The comments focused on the accurate use of collocations rather than how to write good paragraphs.

The second Written Practice Group (16 learners) received the same instructional treatment given to the first Written Group except the instruction on the semantic transparency of collocations. After the treatment, all the experimental groups were post-tested on the immediate learning and delayed retention (two weeks later) of semi-transparent English collocations.

\subsection{Data Analysis}

The normality of distribution and homogeneity of variances of the four groups were checked, and their means on the PET test and collocation pretest were compared through one-way ANOVAs which showed that they were homogeneous in general English proficiency and enjoyed the same knowledge of semitransparent collocations at the outset of the study. The group means on the immediate and delayed semitransparent collocations posttests were compared through a couple of two-way ANOVAs. In the following section, the statistical results of the study are displayed.

\section{Results}

4.1 Comparison of group means on the posttest 1 (Two-way ANOVA)

To test the research hypotheses 1 and 3, the means of the four groups on the immediate semitransparent collocations posttest were submitted to a two-way between-groups analysis of variance (ANOVA). The results are shown in Tables 1 to 12 , below.

Table 1. Descriptive statistics of posttest 1 cross-comparisons

Dependent Variable: Posttest

\begin{tabular}{|c|c|c|c|c|}
\hline Modality Group & Collocation Concept & Mean & $\begin{array}{l}\text { Std. } \\
\text { Deviation }\end{array}$ & $\mathrm{N}$ \\
\hline \multirow[t]{3}{*}{ Oral Group } & $\begin{array}{l}\text { Oral }+\quad \text { Collocation } \\
\text { Concept Instruction }\end{array}$ & 25.00 & 3.10 & 16 \\
\hline & $\begin{array}{l}\text { Oral -Collocation } \\
\text { Concept Instruction }\end{array}$ & 16.76 & 3.73 & 17 \\
\hline & Total & 20.76 & 5.38 & 33 \\
\hline \multirow[t]{3}{*}{$\begin{array}{l}\text { Written } \\
\text { Group }\end{array}$} & $\begin{array}{l}\text { Written + Collocation } \\
\text { Concept Instruction }\end{array}$ & 21.50 & 3.25 & 16 \\
\hline & $\begin{array}{l}\text { Written -Collocation } \\
\text { Concept Instruction }\end{array}$ & 14.56 & 2.39 & 16 \\
\hline & Total & 18.03 & 4.50 & 32 \\
\hline \multirow[t]{5}{*}{ Total } & $\begin{array}{l}\text { Oral }+ \text { Collocation } \\
\text { Concept Instruction }\end{array}$ & 25.00 & 3.10 & 16 \\
\hline & $\begin{array}{l}\text { Oral -Collocation } \\
\text { Concept Instruction }\end{array}$ & 16.76 & 3.73 & 17 \\
\hline & $\begin{array}{l}\text { Written }+ \text { Collocation } \\
\text { Concept Instruction }\end{array}$ & 21.50 & 3.25 & 16 \\
\hline & $\begin{array}{l}\text { Written -Collocation } \\
\text { Concept Instruction }\end{array}$ & 14.56 & 2.39 & 16 \\
\hline & Total & 19.42 & 5.12 & 65 \\
\hline
\end{tabular}


As indicated in Table 1, the mean scores of the four groups on the collocation immediate posttest were different, 25, 16.76, 21.50, and 14.56 for the Oral group + collocation concept instruction, Oral group - collocation concept instruction, the Written group + collocation concept instruction, and Written group - collocation concept instruction, respectively. However, to precisely compare the group means and spot the differences, a two-way between-groups ANOVA was run.

Table 2. Levene's test for equality of error variances: Dependent Variable: Posttest 1

\begin{tabular}{llll}
\hline $\mathrm{F}$ & $\mathrm{df} 1$ & $\mathrm{df} 2$ & Sig. \\
\hline 1.82 & 3 & 61 & .15 \\
\hline
\end{tabular}

To test the assumption of homogeneity of variances as one of the assumptions underlying ANOVA, Levene's test of homogeneity of variances was run, as shown in Table 2, which indicates that there was no significant difference in the variances of the groups on the pretest, $[\mathrm{F}(3,61)=1.82, P=.15>.05]$. Therefore, the assumption of homogeneity of variances was satisfied.

Table 3. Two-way ANOVA for the posttest 1: Tests of between-subjects effects

Dependent Variable: Posttest 1

\begin{tabular}{|c|c|c|c|c|c|c|}
\hline Source & $\begin{array}{lr}\text { Type } & \text { III } \\
\text { Sum } & \text { of } \\
\text { Squares } & \end{array}$ & df & $\begin{array}{l}\text { Mean } \\
\text { Square }\end{array}$ & $\mathrm{F}$ & Sig. & $\begin{array}{l}\text { Partial Eta } \\
\text { Squared }\end{array}$ \\
\hline Corrected Model & $1064.79^{\mathrm{a}}$ & 3 & 354.93 & 35.44 & .000 & .64 \\
\hline Intercept & 24589.91 & 1 & 24589.91 & 2454.98 & .000 & .98 \\
\hline Modality & 132.00 & 1 & 132.00 & 13.18 & .001 & .18 \\
\hline Transparency Instruction & 934.60 & 1 & 934.60 & 93.31 & .000 & .61 \\
\hline $\begin{array}{l}\text { Modality Group * } \\
\text { Transparency }\end{array}$ & 6.84 & 1 & 6.84 & .68 & .412 & .01 \\
\hline Error & 610.99 & 61 & 10.02 & & & \\
\hline Total & 26178.00 & 65 & & & & \\
\hline Corrected Total & 1675.79 & 64 & & & & \\
\hline
\end{tabular}

a. R Squared $=.635$ (Adjusted R Squared $=.62$ )

A two-way between-groups analysis of variance was conducted to explore the impact of modality of contextualizing collocational instruction, i.e., written modality and oral modality, and teaching the concept and realization of semantic transparency on the learning of semantically semitransparent English collocations. The subjects were divided into four groups (Group 1: Oral plus semantic transparency instruction; Group 2: Oral minus semantic transparency instruction; Group 3: Written plus semantic transparency instruction; and Group 4: Written minus semantic transparency instruction). As seen in Table 3 above, there was a statistically significant main effect for modality $[F(1,61)=13.18$, $p=.001$ ], and the effect size was large (partial eta squared $=.18$ ), indicating that modality of contextualization significantly contributed to the learning of collocations. Table 4 below displays further results suggesting the same interpretation. 
Table 4. Main effects of modality

Dependent Variable: Posttest 1

\begin{tabular}{lllll}
\hline & \multirow{2}{*}{ Mean } & Std. Error & \multicolumn{2}{l}{$95 \%$ Confidence Interval } \\
\cline { 3 - 5 } & & & Lower Bound & Upper Bound \\
\hline Oral Group & 20.88 & .55 & 19.78 & 21.99 \\
Written Group & 18.03 & .56 & 16.913 & 19.15 \\
\hline
\end{tabular}

As shown in Table 4 above, the mean score for the oral modality group $(M=20.88)$ was significantly different from the mean score of the written modality group $(\mathrm{M}=18.03)$. Therefore, the first research question in this study is positively answered, indicating that conversation-based contextualization proved significantly more effective than paragraph writing contextualization in contributing to intermediate Iranian EFL learners' learning of semitransparent collocations. However, as shown in Table 3, the interaction effect of modality of contextualization and semantic transparency instruction did not reach statistical significance $[F(1,61)=.68, p=.412]$, and the effect size was small (partial eta squared $=.01$ ), which indicates that the answer to the third research question is clearly negative. Therefore, it can be concluded that semantic transparency instruction did not interact with the modality of contextualization of collocational practice in contributing to learning semitransparent English collocations on the immediate posttest.

Also, a significant main effect was found for transparency instruction $[F(1,61)=93.31, p=.000]$, and the effect size was considerably large (partial eta squared $=.61$ ), as shown in Table 3 above. The results displayed in Table 5 also support this finding.

Table 5. Main effects of transparency instruction

Dependent Variable: Posttest 1

\begin{tabular}{lllll}
\hline \multirow{2}{*}{ Transparency } & \multirow{2}{*}{ Mean } & Std. Error & \multicolumn{2}{l}{$95 \%$ Confidence Interval } \\
\cline { 3 - 5 } & & & Lower Bound & Upper Bound \\
\hline Plus & 23.25 & .56 & 22.13 & 24.37 \\
Minus & 15.66 & .55 & 14.56 & 16.77 \\
\hline
\end{tabular}

As Table 5 above shows, the mean score of the plus transparency instruction group $(\mathrm{M}=23.25)$ was significantly larger than the mean score of the minus transparency instruction group $(M=15.66)$, indicating that teaching semantic transparency significantly influenced the learning of semitransparent collocations, though it did not significantly interact the modality of contextualization (oral versus written modality). 
Table 6. Main effects in terms of transparency instruction for each modality

Dependent Variable: Posttest 1

\begin{tabular}{llllll}
\hline \multirow{2}{*}{ Modality Group } & \multirow{2}{*}{ Mean } & \multirow{2}{*}{ Std. Error } & \multicolumn{2}{l}{$95 \%$ Confidence Interval } \\
\cline { 5 - 6 } Oransparency & & & Lower Bound & Upper Bound \\
\hline \multirow{2}{*}{ Oral Group } & Plus & 25.00 & .79 & 23.42 & 26.58 \\
& Minus & 16.77 & .77 & 15.23 & 18.30 \\
\hline \multirow{2}{*}{ Written Group } & Plus & 21.50 & .79 & 19.92 & 23.08 \\
& Minus & 14.56 & .79 & 12.98 & 16.15 \\
\hline
\end{tabular}

Also, as indicated in Table 6 above, semantic transparency instruction significantly influenced the learning of semitransparent collocations for each modality group. That is, there was a statistically significant difference between the two subgroups in each modality group which had received semantic transparency instruction and those which had not (The mean score of the oral subgroup with semantic transparency instruction $(M=25.00)$ was significantly larger than the mean score of the oral subgroup without semantic transparency instruction $(M=16.77)$. Therefore, semantic transparency instruction did positively contribute to the relevant subgroup's learning of semitransparent collocations. As regards its effect in the written modality group, a similar result was obtained. That is, the mean score of the written subgroup with semantic transparency instruction $(M=21.50)$ was significantly different from the mean score of the written subgroup without semantic transparency instruction $(\mathrm{M}=14.56)$.

\subsection{Comparison of group means on the posttest 2 (Two-way ANOVA)}

To test the research hypotheses 2 and 4, the means of the four groups on the delayed semitransparent collocations posttest were submitted to a two-way between-groups analysis of variance (ANOVA). The results are shown in Tables 7 to 12 , below.

Table 7. Descriptive statistics of posttest 2 cross-comparisons

Dependent Variable: Posttest 2

\begin{tabular}{lllll}
\hline Modality Group & Transparency & Mean & \multicolumn{1}{c}{$\begin{array}{l}\text { Std. } \\
\text { Deviation }\end{array}$} \\
\hline Oral Group & Plus & 23.50 & 2.757 & 16 \\
& Minus & 15.82 & 3.661 & 17 \\
& Total & 19.55 & 5.044 & 33 \\
\hline Written & Plus & 20.56 & 2.966 & 16 \\
Group & Minus & 13.25 & 2.595 & 16 \\
\cline { 2 - 5 } & Total & 16.91 & 4.617 & 32 \\
\hline Total & Plus & 22.03 & 3.188 & 32 \\
& Minus & 14.58 & 3.401 & 33 \\
\cline { 2 - 4 } & Total & 18.25 & 4.981 & 65 \\
\hline
\end{tabular}


As indicated in Table 7, the mean scores of the four groups on the collocation delayed posttest were different, 23.50, 15.82, 20.56, and 13.25 for the Oral group + collocation concept instruction, Oral group - collocation concept instruction, the Written group + collocation concept instruction, and Written group - collocation concept instruction, respectively. However, to precisely compare the group means and spot the differences, a two-way between-groups ANOVA was run. The results are presented in Tables 8 to 12, below.

Table 8. Levene's test for equality of error variances

Dependent Variable: Posttest 2

\begin{tabular}{llll}
\hline $\mathrm{F}$ & $\mathrm{df} 1$ & $\mathrm{df} 2$ & Sig. \\
\hline 1.01 & 3 & 61 & .40 \\
\hline
\end{tabular}

To test the assumption of homogeneity of variances as one of the assumptions underlying ANOVA, Levene's test of homogeneity of variances was run, as shown in Table 8 , which indicates that there was no significant difference in the variances of the groups on the pretest, $[\mathrm{F}(3,61)=1.01, P=.40>.05]$. Therefore, the assumption of homogeneity of variances was satisfied.

Table 9. Two-way ANOVA for the posttest 2: Tests of between-subjects effects

Dependent Variable: Posttest 2

\begin{tabular}{lllllll}
\hline Source & $\begin{array}{l}\text { Type III Sum } \\
\text { of Squares }\end{array}$ & df & Mean Square & F & Sig. & $\begin{array}{l}\text { Partial } \\
\text { Eta } \\
\text { Square } \\
\text { d }\end{array}$ \\
\hline Corrected Model & $1026.65^{\mathrm{a}}$ & 3 & 342.22 & 37.18 & .000 & .65 \\
Intercept & 21714.85 & 1 & 21714.85 & 2359.435 & .000 & .98 \\
Modality Group & 123.30 & 1 & 123.30 & 13.40 & .001 & .18 \\
Transparency & 912.09 & 1 & 912.09 & 99.10 & .000 & .62 \\
Modality Group * Transpare & .54 & 1 & .54 & .06 & .810 & .001 \\
Error & 561.41 & 61 & 9.20 & & & \\
\hline Total & 23228.00 & 65 & & & & \\
\hline Corrected Total & 1588.06 & 64 & & & & \\
\hline a. R Squared = 646 (Adjusted R Squared = .63)
\end{tabular}

To check the effects of modality of contextualizing collocational instruction, i.e., written modality and oral modality, and explicit instruction of the concept and realizations of semantic transparency on the retention of semantically semitransparent English collocations, a two-way between-groups analysis of variance was conducted. As displayed in Table 9 , there was a statistically significant main effect for modality $[F(1,61)=13.40, p=.001]$, and the effect size was large (partial eta squared $=.18$ ), which reveals that modality of contextualizing collocation instruction had a significant delayed effect on the learning of collocations. A glance at the mean scores in Table 10 also provides evidence for this claim. 
Table 10. Main effects of modality

Dependent Variable: Posttest 2

\begin{tabular}{lllll}
\hline & \multirow{2}{*}{ Mean } & Std. Error & \multicolumn{2}{l}{$95 \%$ Confidence Interval } \\
\cline { 3 - 5 } & & & Lower Bound & Upper Bound \\
\hline Oral Group & 19.66 & .53 & 18.61 & 20.72 \\
Written Group & 16.91 & .54 & 15.83 & 17.98 \\
\hline
\end{tabular}

As shown in Table 10 above, the mean score for the oral modality group $(\mathrm{M}=19.66)$ was significantly different from the mean score of the written modality group $(M=16.91)$. Therefore, the answer to the second question in this study is positive, and the corresponding null hypothesis (hypothesis 2) could safely be rejected, indicating that conversationbased contextualization turned out to be more effective than paragraph writing contextualization in influencing intermediate Iranian EFL learners' retention of semitransparent collocations. However, as shown in Table 9, the interaction effect of modality of contextualization and semantic transparency instruction was not statistically significant $[F(1,61)=.06, p=.81]$, and the effect size was very small (partial eta squared $=.001$ ), which indicates that the answer to the fourth research question is negative and the null hypothesis 4 could not be rejected. Therefore, it can be concluded that semantic transparency instruction did not interact with the modality of contextualization of collocational practice in influencing the retention of semitransparent English collocations on a delayed posttest two weeks after the experiment.

Table 11. Main effects of transparency instruction

Dependent Variable: Posttest 2

\begin{tabular}{lllll}
\hline \multirow{2}{*}{ Transparency } & Mean & Std. Error & \multicolumn{2}{l}{$95 \%$ Confidence Interval } \\
\cline { 3 - 5 } & & & Lower Bound & Upper Bound \\
\hline Plus & 23.03 & .54 & 20.96 & 23.10 \\
Minus & 14.54 & .53 & 13.48 & 15.60 \\
\hline
\end{tabular}

Although semantic transparency instruction did not interact with the modality-oriented contextualization, as it can be observed in Table 9, its main effect on the retention of semitransparent collocations on the delayed posttest reached statistical significance $[F(1,61)=99.10, p=.000]$, and the effect size was considerably large (partial eta squared $=$ .62). As Table 11 above indicates, the mean score of the plus transparency instruction group $(\mathrm{M}=23.03)$ was significantly larger than the mean score of the minus transparency instruction group $(\mathrm{M}=14.54)$, which indicates that teaching semantic transparency turned out to be positively facilitating the retention of semitransparent collocations on the delayed posttest. So, in response to the research question 4, it could be said that semantic transparency instruction did not interact with the modality of contextualization of collocational retention, but it did contribute to a long-term effect on the retention of collocations by itself. 
Table 12. Main effects in terms of transparency instruction for each modality

Dependent Variable: Posttest 2

\begin{tabular}{|c|c|c|c|c|c|}
\hline \multirow[b]{2}{*}{ Modality Group } & \multirow[b]{2}{*}{ Transparency } & \multirow{2}{*}{ Mean } & \multirow{2}{*}{ Std. Error } & \multicolumn{2}{|c|}{ 95\% Confidence Interval } \\
\hline & & & & Lower Bound & Upper Bound \\
\hline \multirow{2}{*}{ Oral Group } & Plus & 23.50 & .76 & 21.98 & 25.02 \\
\hline & Minus & 15.82 & .74 & 14.35 & 17.30 \\
\hline \multirow{2}{*}{ Written Group } & Plus & 20.56 & .76 & 19.05 & 22.08 \\
\hline & Minus & 13.25 & .76 & 11.73 & 14.77 \\
\hline
\end{tabular}

As indicated in Table 12 above, semantic transparency instruction significantly enhanced the retention of semitransparent collocations for both modality groups. That is, a statistically significant difference was found between the subgroups in each modality group which had received semantic transparency instruction and those which had not received such an instructional treatment (The mean score of the oral subgroup with semantic transparency instruction $(\mathrm{M}=23.50)$ was significantly larger than the mean score of the oral subgroup without semantic transparency instruction $(M=15.82)$. Therefore, semantic transparency instruction did positively contribute to the relevant subgroup's retention of semitransparent collocations. A similar result was obtained in terms of its effect on the retention of semitransparent collocations in the written modality group. The mean score of the written subgroup with semantic transparency instruction $(\mathrm{M}=20.56)$ was significantly larger than the mean score of the written subgroup without semantic transparency instruction $(\mathrm{M}=13.25)$.

\section{Discussion}

With respect to research question 1, the findings of this study provide support for the effect of modality of contextualizing collocation teaching on the learning of semitransparent English collocations. Generally, the finding that contextualization contributed to learning, though only in favor of oral contextualization, endorses the positive effect attributed to contextual teaching on learning linguistic elements in general, and learning and retention of vocabulary and idioms in particular (McCarthy, 1990).

More specifically, the one important piece of evidence in this respect was that embedding collocation teaching and practice in oral activities and tasks proved more effective in facilitating the learning of collocation. This finding could be interpreted with reference to the fact that in the oral modality, the learners were more actively engaged in the learning process, as they had to prepare and practice the conversations on themselves and then act them out which was further reflected upon chorally in class. This, in addition to being in line with Swain's (1985) output hypothesis and the role of output in facilitating learners' linguistic knowledge, bears witness to the attested role of interaction and apperception in driving inter-language forward (Gass, 1997; Long, 1991).

There seemed to have been much interaction and, consequently, apperception of the self-generated and subsequently negotiated linguistic input in the oral group, which could have contributed to the better learning of collocations by that group. This finding is in accordance with the finding obtained in Khabiri and Masoumpanah (2012) who found that although both oral and written contextualization groups outperformed the control group in learning idioms, the oral group further outperformed the written group.

In sum, oral practice proved more effective in fostering learners' consciousness and engagement which, in turn, more effectively contributed to the noticing and internalization of the collocations under study. As far as mere contextualization irrespective of modality is concerned, this finding agrees with those in Mirhassani and Talebi (2007) and Zarei and Tondaki (2015) and Zaabalawi and Gould (2017) who found that sentence writing significantly facilitated the retention and recognition of idioms.

The finding has practical significance for teaching different aspects of a second language in that it provides insights about the facilitating role of contextualization in L2 instruction. More specifically, this finding encourages the 
effectiveness of oral contextualization as a more likely element for enhancing the noticing and acquisition of grammatical and lexical elements of a second language.

Regarding research question 2, this study provides evidence supporting the long-term effect of contextualization on the retention of collocations by Iranian EFL learners. Interestingly, similar results were obtained regarding the effects of oral and written contextualization on the long-term retention of collocations. This, again, could be interpreted as implying that the noticing and apperception functions of the higher degrees of engagement and interaction in the oral modality are much likely to have rendered the retention of collocations more plausible and feasible. Therefore, the general conclusion out of the findings so far could be that embedding the teaching and practice of collocations in oral activities seems to better enhance the immediate learning and long-term retention of collocations compared to writingbased contextualization and practice.

As regards research questions 3 and 4, the finding indicated that semantic transparency instruction and modality of contextualization did not interact in influencing the immediate learning of collocations, which supports the unequivocal and consistent role of such instruction on the learning of semitransparent collocations irrespective of the modality of contextualization. In other words, the results indicated that the effects of teaching the concept and realizations of semantic transparency of collocations were not bound to either of the two modalities and semantic transparency instruction influenced the immediate learning and long-term retention of collocations across both modalities. This finding corroborates Mahdavi-Zafarghandi and Emamzadeh's (2016) conclusion that explicit instruction of collocations facilitates their comprehension and production.

More importantly, this finding agrees with those found in Gyllstad and Wolter (2015) who investigated the effect of the degree of semantic transparency of collocations on their processing by L2 learners and found that the semantically semi-transparent nature of collocations played an important role in collocational processing. It is also in line with Frisson, Niswander-Klement, and Pollatsek's (2008) conclusion that when the constituents of a collocation are considered as a whole unit, the degree of semantic transparency highly influences the processing of English collocations.

Now, the bottom line of all of the preceding section would relate to Nesselhauf's $(2003,2005)$ contention about the problematicity of semantically semitransparent English collocations for L2 learners. He proposed this contention on the ground that semantically semitransparent collocations are neither fully transparent and hence subject to learners' consciousness and noticing nor fully non-transparent and, therefore, likely to prompt attention and reflection. Therefore, they are very unlikely to be attended to by L2 learners and will consequently be ignored. The findings in this study relating to the effects of semantic transparency instruction on learning and retention of semitransparent collocations would suggest that Nesselhauf's $(2003,2005)$ warning was a valid one in that the learners in both modality groups who were provided with instruction on the concept of semantic transparency and foregrounding of its saliency and collocational realizations significantly and meaningfully outperformed other learners in the immediate intake and subsequent retention of semantically semitransparent collocations.

These findings can be of practical significance for second language teachers by highlighting the importance of the degree of transparency of linguistic elements in the route and rate of their processing, internalization, and long-term retention by L2 learners. Furthermore, they provide language teachers with the invaluable insight that different techniques and differential degrees of consciousness-raising attempts will be needed for teaching elements with varying degrees of transparency.

\section{Conclusion}

The role of noticing and raising second language learners' consciousness about the formal devices of a second language has been reiterated in SLA literature (Schmidt, 1990). Noticing is, in fact, a function of both the language learners' attention and the saliency of the linguistic form(s) to be learned. One problem relating to the learning of collocations which has been recognized by Nesselhauf $(2003,2005)$ as the nature of semantically semitransparent English collocations constituted part of the impetus of the present study. As these collocations, by their nature, seem to be neither completely salient and recognizable nor truly opaque and, hence, triggering attention, the need was felt to highlight the concept of semantic transparency of the collocations and its differential degrees in order to foreground their configuration and the semantic relations holding between their constituents, hoping to make them salient for L2 learners. Such consciousness-raising, along with embedding the teaching of collocations primarily within the oral modality proved effective in learning and remembering semitransparent collocations and, therefore, could be 
considered important design features in the methodology of SLA studies. The findings provide evidence supporting the role of proper contextualization and saliency enhancement for the learning of linguistic forms in general, and the otherwise unattended-to semitransparent collocations in particular. In other words, the importance of the findings actually transcends the boundaries of this study in that the techniques utilized could be applied to the teaching of other linguistic forms, be it lexical, grammatical, and phonological.

\section{References}

Ackerman, K., \& Chen, Y. (2013). Developing the academic collocation list (ACL)-A corpus-driven and expert- judged approach. Journal of English for Academic purposes, 12(4), 235-247. https://doi.org/10.1016/j.jeap.2013.08.002

Barfield, A., \& Gyllstad, H. (2009). Researching collocations in another language: Multiple interpretations. Basingstoke: Palgrave Macmillan.

Bartsch, S. (2004). Structural and functional properties of collocations in English. Tübingen, Gunter Narr Verlag Tübingen.

Boers, F., Dang, T. C., \& Strong, B. (2017). Comparing the effectiveness of phrase-focused exercises. A partial replication of Boers, Demecheleer, Coxhead, and Webb (2014). Language Teaching Research, 21(3), $362-380$. doi: $10.1177 / 1362168816651464$

Ellis, N. C. (2001). Memory for language. In P. Robinson (Ed.), Cognition and second language instruction (pp. 33-68). Cambridge: Cambridge University Press.

Ellis, N. C. (2003). Constructions, chunking and connectionism: the emergence of second language structure. In C. J. Doughty \& M. H. Long (Eds.), The handbook of second language acquisition. Oxford: Blackwell.

Ellis, N. C. (2005). At the interface: Dynamic interactions of explicit and implicit language knowledge. Studies in Second Language Acquisition, 27(2), 305-352. doi: https://doi.org/10.1017/S027226310505014X

Firth, J. (1957). Modes of meaning. In F. Palmer (Ed.), Papers in linguistics (pp. 190-215). London: Oxford University Press.

Frisson, S., Niswander-Klement, E., \& Pollatsek, A. (2008). The role of semantic transparency in the processing of English compound words. British Journal of Psychology, 99(1), 87-107. https://doi.org/10.1348/000712607X181304

Gass, S. (1997). Input, interaction and the second language learner. Mahwah, NJ: Lawrence Erlbaum Associates.

Gitzaki, C. (1999). Second language lexical acquisition: A study of the development of collocational knowledge. San Francisco: International Scholar Publications.

Godfroid, A., Boers, F., \& Housen, A. (2013). An eye for words: Gauging the role of attention in L2 vocabulary acquisition by means of eye-tracking. Studies in Second Language Acquisition 35(3), 483-517. https://doi.org/10.1017/S0272263113000119

Granger, S., \& Meunier, F. (2008). Phraseology. An interdisciplinary perspective. Amsterdam: Benjamins.

Granger, S., \& Pacquot, M. (2008). Disentangling the phraseological web. In S. Granger \& F. Meunier (Eds.), Phraseology: An interdisciplinary perspective (pp. 27-49). Amsterdam: Benjamins.

Gyllstad, H., \& Wolter, B. (2015). Collocational processing in light of the phraseological continuum model: Does semantic transparency matter? Language Learning, 66(2), 296-323. doi: 10.1111/lang.12143

Henriksen, B. (n.d.). Research on L2 learners' collocational competence and development: A progress report. Eurosla Monographs Series 2, L2 Vocabulary Acquisition, Knowledge and Use, 29-56.

Hoey, M. (2005). Lexical priming: A new theory of words and language. London: Routledge.

Jackson, H. (1988). Words and their meaning. London: Longman Group UK Limited.

Jiang, J. (2009). Designing pedagogic materials to improve awareness and productive use of L2 collocations. In A. Barfield \& H. Gyllstad (Eds.), Researching collocations in another language: Multiple interpretations (pp. 99113). Basingstoke: Palgrave Macmillan. 
Keshavarz, M. H., \& Taherian, P. (2018). The effect of explicit instruction of collocations on EFL learners' language proficiency. Hacettepe University Journal of Education, 33(4), 987-1001. doi: 10.16986/HUJE.2018038632

Khabiri, M., \& Masoumpanah, Z. (2012). The comparative effect of using idioms in conversation and paragraph writing on EFL learners' idiom learning. Iranian Journal of Applied Language Studies, 4(1), 59-80. https://ijals.usb.ac.ir/article_1348.html

Khoda Reza, M., \& Ashouri, S. (2016). The effect of lexical collocation instruction on intermediate EFL learners' vocabulary size. Indian Journal of Fundamental and Applied Life Sciences, (S1), 416-425. https://pingpdf.com/pdf-the-effect-of-lexical-collocation-instruction-on-intermediate-efl-cibtech.html

Koya, T. (2005). The acquisition of basic collocations by Japanese learners of English (Unpublished doctoral dissertation). Waseda University, Japan.

Laufer, B., \& Waldman, T. (2011). Verb-noun collocations in second-language writing: A corpus analysis of learners' English. Language Learning, 61(2), 647-672. https://doi.org/10.1111/j.1467-9922.2010.00621.x

Lewis, M. (2000). Teaching collocation: Further developments in the lexical approach. Hove: Language Teaching Publications.

Long, M. (1991). Focus on form: A design feature in language teaching methodology. In K. de Bot, R. Ginsberg, \& C. Kramsch (Eds.), Foreign language research in cross-cultural perspective (pp. 39-52). Amsterdam: John Benjamins.

Mahdavi-Zafarghandi, A., \& Emamzadeh, S. (2016). The effect of teaching lexical collocations on Iranian EFL learners' writing ability: Focusing on the appropriate use of collocations. Journal of Applied Linguistics and Language Research, 3(5), 107-117. https://www.semanticscholar.org/paper/The-Effect-of-Teaching-LexicalCollocations-on-EFL-Mahdavi-Zafarghandi-Emamzadeh/32e14846fed6349b11e7f053fcb0053534c6a127

McCarthy, M. (1990). Vocabulary. Oxford: Oxford University Press.

Melcuk, I. (1998). Collocations and lexical functions. Oxford: Clarendon. 2(1), 23-54.

Milton, J. (2009). Measuring second Language vocabulary acquisition. Clevedon: Multilingual Matters.

Mirhassani, A., \& Talebi, S. (2007). The effects of sentence writing on Iranian intermediate EFL learners' retention of idiomatic expressions. Roshd FLT Journal, 22(2), 38-44.

Nation, I. S. P. (2001). Learning vocabulary in another language. Cambridge: Cambridge University Press.

Nesselhauf, N. (2003). The use of collocations by advanced learners of English and some implications for teaching. Applied Linguistics, 24(2), 223-242. http//doi.org/10.1093/applin/24.2.223

Nesselhauf, N. (2005). Collocations in a learner corpus. Amsterdam: John Benjamins.

Palmer, H. (1938). A grammar of English words. London: Longman.

Peters, E. (2016). The learning burden of collocations: The role of interlexical and intralexical factors. Language Teaching Research, 20(1), 113-138. https://limo.libis.be/primoexplore/fulldisplay?docid=LIRIAS1532708\&context=L\&vid=Lirias\&search_scope=Lirias\&tab=default_tab\&l ang=en_US\&fromSitemap $=1$

Pie, C. (2008). Review of empirical studies on collocations in the field of SLA. CELEA Journal, $31(6), 82$. https://wenku.baidu.com/view/76c9f5659b6648d7c1c7461e.html?re=view

Reza, K., \& Ashouri, S. (2016). The effect of lexical collocation instruction on intermediate EFL learners' vocabulary size. Indian Journal of Fundamental and Applied Life Sciences, 6(1), 416-425. www.cibtech.org/sp.ed/j1s/2016/01/jls.htm

Schmitt, N. (2004). (Ed.). Formulaic sequences: Acquisition, processing and use. Amsterdam: Benjamins.

Schmidt, R. (1990). The role of consciousness in second language learning. Applied Linguistics, 11(2), 129-158. http//doi.org/10.1093/applin/11.2.129 
Shehata, A. K. (2008). LI influence on the reception and production of collocations by advanced ESL/EFL Arabic learners of English (Unpublished Ph.D. dissertation). Athens: OH: Ohio University.

Simpson, R., \& Mendis, D. (2003). A corpus-based study of idioms in academic speech. TESOL Quarterly, 37(3), 419438. doi:10.2307/3588398

Slezak, V. (2015). How to teach: Teaching collocations in the EFL classroom. http://www.eflmagazine.com/teachingcollocations-efl-classroom

Snoder, P. (2017). Improving English learners' productive collocation knowledge: The effects of involvement load, spacing, and intentionality. TESL Canada Journal/Revue TESL Du Canada, 34(3), 140-164. http://dx.doi.org/10.18806/tesl.v34i3.1277

Sonbul, S., \& Schmitt, N. (2013). Explicit and implicit lexical knowledge: acquisition of collocations under different input conditions. Language Learning, 63(1), 121-159. https://doi.org/10.1111/j.1467-9922.2012.00730.x

Swain, M. (1985). Communicative competence: some roles of comprehensible input and comprehensible output in its development. In R. Ellis (2008), The study of second language acquisition. Oxford: Oxford University Press.

Szudarski, P., \& Carter, R. (2016). The role of input flood and input enhancement in EFL learners' acquisition of collocations. International Journal of Applied Linguistics, 26(2), 245-265. https://doi.org/10.1111/ijal.12092

Ünver, M. M. (2018). Lexical collocations: issues in teaching and ways to raise awareness. European Journal of English Language Teaching, 3(4), 114-125. doi:10.5281/zenodo.1344700

Vural, E. (2010). Explicit and incidental teaching of English verb-noun collocations in an EFL context. Anadolu University Graduate School of Educational Sciences. Anadolu, Turkey.

Webb, S., \& Kagimoto, E. (2011). Learning collocations: Do the number of collocates, position of the node word, and synonymy affect learning. Applied Linguistics, 32(3), 259-276. https://doi.org/10.1093/applin/amq051

Wood, D. (2010). Perspectives on formulaic language: Acquisition and communication. London/New York: Continuum.

Zaabalawi, R. S., \& Gould, A. M. (2017). English collocations: A novel approach to teaching the language's last bastion. Ampersand, 4(2), 21-29. doi:org/10.1016/j.amper.2017.03.002

Zarei, A. A., \& Tondaki, N. (2015). The effects of explicit and implicit instructional techniques on Iranian EFL learners' comprehension and production of lexical collocations. Academie Royale des Seances Doutr-Mer Bulletin des Seances, 4(2),

122-131. https://www.researchgate.net/publication/312470798_The_Effects_of_Explicit_and_Implicit_Instructional_Tec hniques_on_Iranian_EFL_Learners\%27_Comprehension_and_Production_of_Lexical_Collocations

Zhang, X. (2017). Effects of receptive-productive integration tasks and prior knowledge of component words on L2 collocation development. System, 66(6), 156-167. https://doi.org/10.1016/j.system.2017.03.019

Zou, D. (2017). Vocabulary acquisition through cloze exercises, sentence-writing and composition-writing: Extending the evaluation component of the involvement load hypothesis. Language Teaching Research, 21(1), 54-75. doi: $10.1177 / 1362168816652418$ 